Note

\title{
A Quantification and Confirmation Method of Patulin in Apple Juice by GC/MS
}

(Received December 24, 2003)

\author{
Setsuko Tabata ${ }^{\dagger}$, Kenji Iida, Jin Suzuki, Keisuke Kimura, Akihiro Ibe \\ and Kazuo SAito \\ (Tokyo Metropolitan Institute of Public Health: \\ 3-24-1 Hyakunin-cho, Shinjuku-ku, Tokyo 169-0073, Japan; \\ ${ }^{\dagger}$ Corresponding author)
}

\begin{abstract}
A sensitive and selective method for quantification and confirmation of patulin in apple juice by GC/MS was developed. By this method, patulin was precisely determined and confirmed down to the level of 1 and $5 \mu \mathrm{g} / \mathrm{kg}$ in samples, respectively. Patulin was extracted with ethyl acetate from a sample and then hexane was added to the concentrated extract solution. Significant amounts of insoluble impurities were filtered off, followed by further clean-up by solid-phase extraction with combined silica gel and Florisil cartridges. The filtration step in a low-polarity condition was very effective to remove the impurities in the sample extract solution. The eluate from the cartridges was evaporated to dryness under reduced pressure and patulin was determined and confirmed by GC/MS after derivatization with 2.5\% N,O-bis(trimethylsilyl)trifluoroacetamide ethyl acetate solution. Patulin was determined in the selected ion monitoring mode $(m / z 226)$ and confirmed in the SCAN mode $(m / z 40-340)$. The recovery from apple juice spiked with $10-500 \mu \mathrm{g} / \mathrm{kg}$ ranged from 93.4 to $100 \%$. The limits of detection and quantification were $0.1(S / N=3)$ and $1 \mu \mathrm{g} / \mathrm{kg}(S / N=30)$ of patulin in samples, respectively. Levels down to $5 \mu \mathrm{g} /$ $\mathrm{kg}$ of patulin in sample were readily confirmed.
\end{abstract}

Key words: patulin; apple juice; analysis; GC/MS; confirmation; mass spectrum

\section{Introduction}

Patulin is a mycotoxin produced by many species of Penicillium, Aspergillus and Byssochlamys ${ }^{1)}$. It is known that patulin is unstable under alkaline conditions $(\mathrm{pH}>$ 7). Patulin is toxic to many kinds of animals, such as mouse, rat, hamster, dog and chicken with $\mathrm{LD}_{50}$ values ranging from 5 to $170 \mathrm{mg} / \mathrm{kg}^{2}$.

Regulatory limits have been established for patulin by several countries in various foods, mainly apple juice. The most common limit is $50 \mu \mathrm{g} / \mathrm{kg}^{3)}$. In 2003 the Codex Committee on Food Additives and Contaminants adopted a maximum level of $50 \mu \mathrm{g} / \mathrm{kg}$ for patulin. In Japan, a maximum level of $50 \mu \mathrm{g} / \mathrm{kg}$ was set for patulin in apple juice by the Ministry of Health, Labor and Welfare on November 26 in 2003 and will come into force on June 1 in $2004^{4}$.

Generally, analytical methods should be able to determine the object at the level of one tenth of the regulation limit. Furthermore, as patulin is a mycotoxin, a very toxic substance, we should confirm patulin in all positive samples. Therefore, a method, which can determine and confirm patulin at the level of $5 \mu \mathrm{g} / \mathrm{kg}$ in sample, is needed. Among the methods so far developed for the analysis of patulin in apple juice, the method consisting of extraction with ethyl acetate, clean-up with sodium carbonate solution, concentration and quantification by reversed-phase liquid chromatography (LC) with ultraviolet (UV) detection is most widely used and has been adopted as the AOAC official method $^{5)}$. Although this method is applicable to determination of $20-200 \mu \mathrm{g}$ patulin/L of apple juice ${ }^{5)}$, many interfering peaks on the liquid chromatogram often make it difficult to determine the content of patulin precisely. Further, it is also difficult to confirm patulin by UV spectroscopy, because the UV spectra of the interfering peaks near to patulin are very similar to that of patulin.

For confirmation of a given compound, comparison of mass spectra obtained by GC/MS is considered to be very reliable, because characteristic fragment ions are formed by electron impact ionization. LC/MS is regarded as inferior to GC/MS for confirmation, because only a few fragment ions are available under usual conditions and the fragment patterns of mass spectra vary with the conditions of HPLC and MS.

Although some methods using GC/MS have been developed for analysis of patulin in apple juice ${ }^{6)-9)}$, they are not sensitive enough to quantify and confirm patulin at the $5 \mu \mathrm{g} / \mathrm{kg}$ level. Rychlik and Schieberle reported a highly sensitive method by GC/high-resolution mass spectrometry (HRMS) using ${ }^{13} \mathrm{C}$-labeled patulin as a surrogate ${ }^{10)}$. Although HRMS may be a highly sensitive and selective method, it has not been commonly 
used because it is very expensive. Rupp and Turnipseed reported a confirmation method for patulin in apple juice by $\mathrm{GC} / \mathrm{MS}^{6)}$. The extraction and clean-up procedures in this method were almost the same as those in the AOAC method. By this method, patulin in samples was confirmed at the level of $30-400 \mu \mathrm{g} / \mathrm{L}$.

In this study, we developed a GC/MS method, by which patulin can be precisely determined with a quantification limit of $1 \mu \mathrm{g} / \mathrm{kg}$ and confirmed down to the level of $5 \mu \mathrm{g} / \mathrm{kg}$, one-tenth of the regulatory limit in Japan, in samples.

\section{Materials and Methods}

\section{Reagents}

Standard stock solution (100 $\mu \mathrm{g} / \mathrm{mL}): 5 \mathrm{mg}$ of patulin (Sigma Chemicals Co., St. Louis, MO, USA) was dissolved in $50 \mathrm{~mL}$ of ethyl acetate. This solution was stored in a refrigerator $\left(<5^{\circ} \mathrm{C}\right)$.

Standard working solution: The stock solution was diluted with ethyl acetate to make a concentration of 2 $\mu \mathrm{g} / \mathrm{mL}$.

Organic solvents: ethyl acetate and hexane of special grade and acetonitrile of HPLC grade were from Wako Pure Chemical Industries, Ltd. (Osaka, Japan).

Water for HPLC mobile phase: water purified with a Milli-Q purification system (Waters Co., Milford, MA, USA).

Cartridge columns: Sep-Pak Plus silica and Sep-Pak Plus Florisil were from Waters Co (Milford, MA, USA). A Sep-Pak Plus Florisil cartridge column was connected under a Sep-Pak Plus silica cartridge column. They were conditioned with $10 \mathrm{~mL}$ each of ethyl acetate and hexane before use.

Derivatizing agent: $\mathrm{N}, \mathrm{O}$-Bis(trimethylsilyl)trifluoroacetamide (BSTFA) was from GL Sciences (Tokyo, Japan).

Acetic acid solution ( $\mathrm{pH} 4$ ): Water was adjusted to pH 4 with acetic acid.

Filter: Polytetrafluoroethylene (PTFE) membrane filter combined with a pre-filter of glass fiber, $0.45 \mu \mathrm{m}$ in pore size and $25 \mathrm{~mm}$ in diameter, was from Whatman Co. (Maidstone, Kent, UK)

\section{Apparatus}

GC/MS: GC-17A gas chromatograph with a QP-5000 mass spectrometer and a Class 5000 system as a data processor (Shimadzu, Kyoto, Japan).

HPLC system: Gulliver series (JASCO Co., Tokyo, Japan) integrated with a model PU-2089 pumping system, a model AS-1555-10 auto sampler injector, a model UV-2070 UV-VIS detector, and a Borwin system as a data processor.

\section{Determination of patulin by AOAC official methods of analysis $995.10^{5)}$}

A $5 \mathrm{~mL}$ aliquot of sample was extracted twice with 10 $\mathrm{mL}$ of ethyl acetate and the combined extract solution was washed with $2 \mathrm{~mL}$ of $1.5 \%$ sodium carbonate solution. The aqueous layer was extracted with $4 \mathrm{~mL}$ of ethyl acetate. The ethyl acetate layers were combined and evaporated to dryness, dissolved in $1 \mathrm{~mL}$ of acetic acid solution ( $\mathrm{pH} 4$ ) and applied to an HPLC system.

\section{Sample preparation of the proposed method}

1. Extraction

After addition of $10 \mathrm{~g}$ of sodium chloride, $50 \mathrm{~g}$ of apple juice was extracted twice with $100 \mathrm{~mL}$ of ethyl acetate in a $300 \mathrm{~mL}$ separatory funnel by shaking for 10 min. Ethyl acetate fractions were combined and evaporated to dryness under reduced pressure at $35^{\circ} \mathrm{C}$ and then the residue was mixed well with $5 \mathrm{~mL}$ of ethyl acetate, and sonicated for $30 \mathrm{sec}$. This solution is hereinafter called "sample extract".

If the sample was an apple juice concentrate, $50 \mathrm{~mL}$ of water was added to $50 \mathrm{~g}$ of sample before extraction to reduce the viscosity. Then $20 \mathrm{~g}$ of sodium chloride was added and the mixture was extracted twice with 200 $\mathrm{mL}$ of ethyl acetate in a $500 \mathrm{~mL}$ separatory funnel by shaking for $10 \mathrm{~min}$. The following procedure was the same as described above.

\section{Clean-up and derivatization}

Two mL of "sample extract" was pipetted into a 20$30 \mathrm{~mL}$ flask or tube, to which $18 \mathrm{~mL}$ of hexane was added and mixed well. Insoluble impurities were filtered off with a PTFE membrane filter combined with a pre-filter of glass fiber, and the filtrate was loaded onto combined silica and Florisil cartridge columns. The columns were washed with $10 \mathrm{~mL}$ of hexane-ethyl acetate $(4: 1)$ and eluted with $10 \mathrm{~mL}$ of ethyl acetate. The eluate was evaporated to dryness under reduced pressure at $35^{\circ} \mathrm{C}$.

The residue was dissolved in $0.5 \mathrm{~mL}$ of freshly prepared 2.5\% BSTFA ethyl acetate solution and kept at room temperature for $1 \mathrm{hr}$. This solution is hereinafter called "test solution for GC/MS".

\section{Determination and confirmation of the proposed method}

Patulin was determined by GC/MS in the selected ion monitoring (SIM) mode. The monitoring ions were $\mathrm{m} / z$ 226, 183 and 170, and quantification of patulin was based on the peak area of the $m / z 226$ ion. Positive samples were confirmed for patulin in the SCAN mode with the range of $m / z 40-340$. The mass spectrum of the peak with a similar retention time to patulin in the sample was compared with that of patulin standard. The conditions of GC/MS were as follows: column, BPX35 capillary column $(0.22 \mathrm{~mm}$ i.d. $\times 25 \mathrm{~m}, 0.25 \mu \mathrm{m}$ film thickness, SGE Co., Cupertino, CA, USA); oven temperature, $80^{\circ} \mathrm{C}(2 \mathrm{~min}) \rightarrow 150^{\circ} \mathrm{C}\left(10^{\circ} \mathrm{C} / \mathrm{min} \rightarrow 230^{\circ} \mathrm{C}\left(5^{\circ} \mathrm{C} / \mathrm{min}\right.\right.$, $15 \mathrm{~min})$; injection, $1 \mu \mathrm{L}$, splitless, $200^{\circ} \mathrm{C}$; detector, EI, $230^{\circ} \mathrm{C}$; electron energy, $70 \mathrm{eV}$; carrier gas, helium (constant pressure mode at $100 \mathrm{kPa}$ ).

\section{Results and Discussion}

\section{Analysis of patulin by HPLC}

Liquid chromatograms of the patulin standard and sample purified and analyzed by the AOAC official methods of analysis $995.10^{5)}$ are shown in Fig. 1. Many 
interfering peaks followed after that of 5-hydroxymethylfurfural (HMF). Although this sample did not contain more than $1 \mu \mathrm{g}$ patulin $/ \mathrm{kg}$, there was a peak

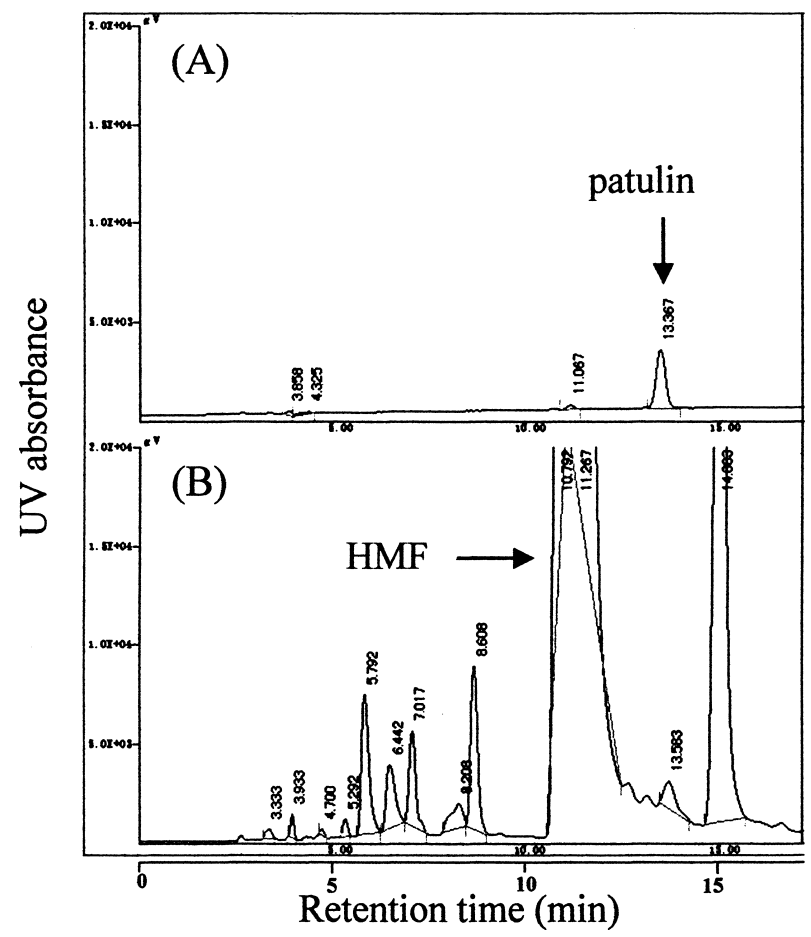

Fig. 1. Liquid chromatograms of standard and sample (A) Standard, $20 \mu \mathrm{g} / \mathrm{kg}$ equivalent in sample, (B) Sample, cleaned up by AOAC Official Methods for Analysis 995.10, patulin content: not more than 1 $\mu \mathrm{g} / \mathrm{kg}$

Column: Puresil $\mathrm{C}_{18}$, mobile phase: $0.095 \%$ perchloric acid $(60 \%): \mathrm{CH}_{3} \mathrm{CN}(97: 3)$, flow rate: 1.0 $\mathrm{mL} / \mathrm{min}$, detection: UV $(276 \mathrm{~nm})$, injection volume: $20 \mu \mathrm{L}$.
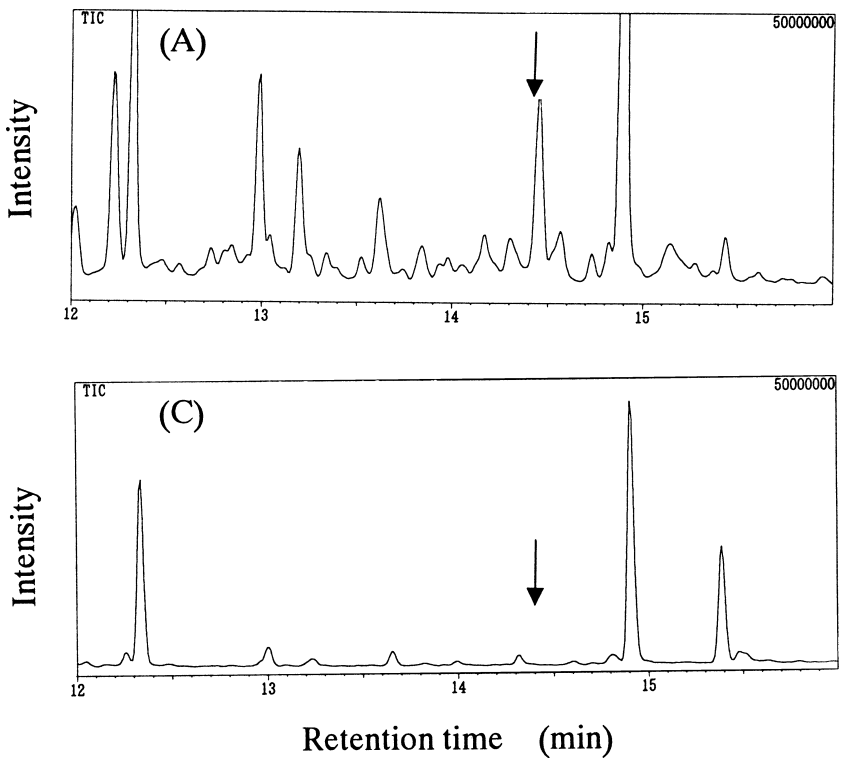

with a similar retention time to patulin. The retention time of the peak was a little different from that of patulin, and at least 2 peaks overlapped. We found no way to determine patulin in this sample by HPLC. In some cases, precise quantification of patulin at a low level by HPLC was difficult. Moreover, it was difficult to confirm whether a peak with a similar retention time to patulin was patulin or not, because the UV spectra of patulin and HMF are very similar to each other.

\section{Development of clean-up procedure}

Even without clean-up after extraction, it was possible to determine patulin roughly in most apple juice samples by SIM mode analysis. However, injection of a solution containing a lot of impurities usually causes problems with the ion source of the MS detector and the capillary column. Some clean-up procedures are necessary for the sensitive and selective analysis of patulin.

1. Washing with sodium carbonate solution

Washing with 1.5\% sodium carbonate solution after extraction is the clean-up step in the AOAC official method of analysis $995.10^{5}$. This washing step had an insufficient effect for determining patulin at low level; it was not possible to confirm patulin at less than $20 \mu \mathrm{g} /$ $\mathrm{kg}$ in sample by mass spectrometry. As patulin is also known to be unstable in an alkaline environment, we omitted this step.

2. Filtration in low-polarity condition and solidphase extraction

In the AOAC official method of analysis $974.18^{5)}$, patulin was cleaned up by silica gel column chromatography. In the clean-up procedure, however, benzene, a very harmful solvent, was used. Therefore we developed a new clean-up step using other solvents.

When "sample extract" (ethyl acetate solution) was
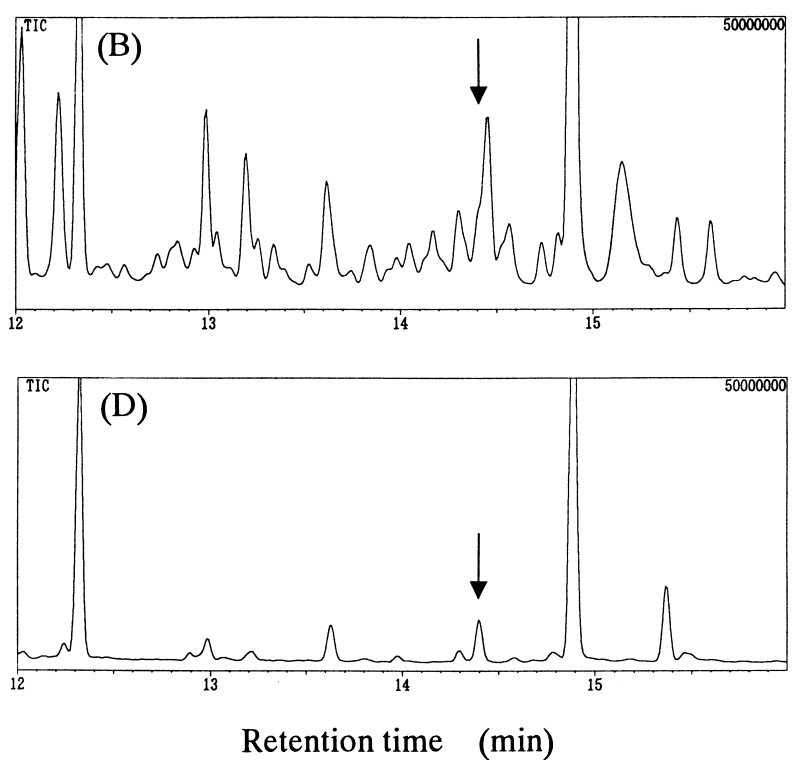

Fig. 2. Mass chromatograms in scan mode of the sample after each clean-up step

(A) Blank sample after filtration, (B) Spiked sample $(50 \mu \mathrm{g} / \mathrm{kg})$ after filtration, (C) Blank sample after clean-up by solid-phase extraction, (D) Spiked sample $(50 \mu \mathrm{g} / \mathrm{kg})$ after clean-up by solid-phase extraction Each test solution for GC/MS analysis contained $20 \mathrm{~g}$ equivalent of the sample.

The arrows show the retention time for the patulin derivative. 


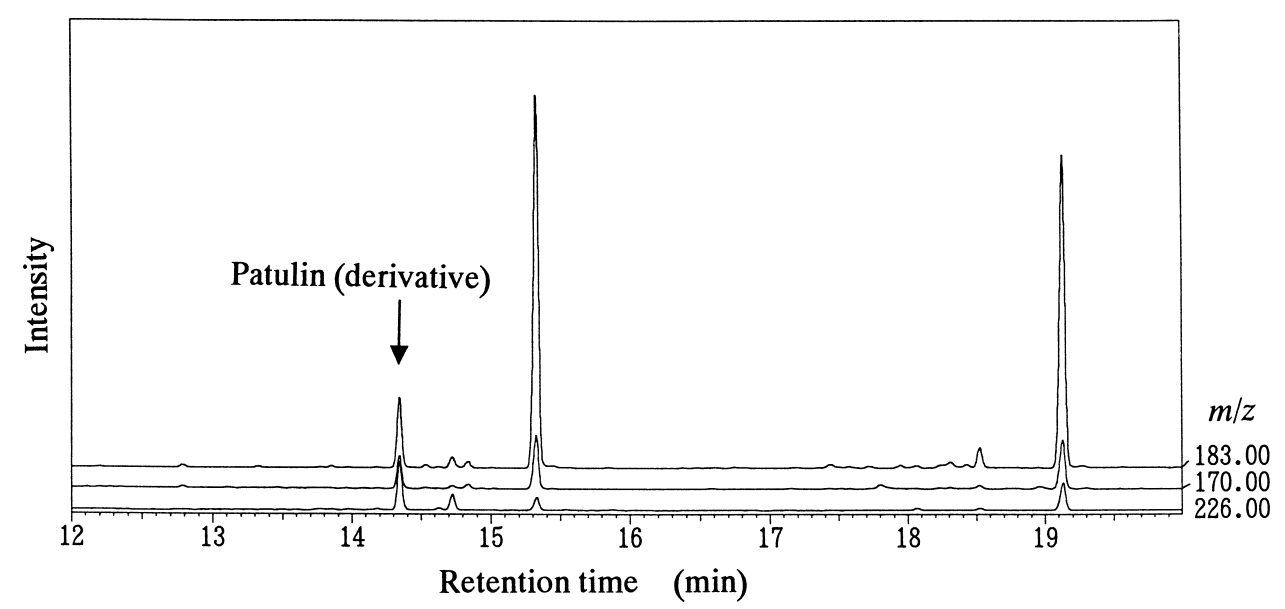

Fig. 3. Mass chromatogram of patulin TMS derivative in sample Patulin content: $5.5 \mu \mathrm{g} / \mathrm{kg}$ in sample.

directly applied to combined silica and Florisil cartridges, patulin passed through, while some impurities were held in the cartridges. The eluent was evaporated, and the residue was taken up in BSTFA solution and subjected to GC/MS analysis. Little improvement by this clean-up was observed in the mass chromatogram and mass spectra. In this study, therefore, hexane was added to the "sample extract" to hold patulin on the cartridges. Patulin was completely retained on the cartridges in hexane-ethyl acetate mixed solution containing more than $80 \%$ of hexane. By washing the cartridges with $10 \mathrm{~mL}$ of hexane-ethyl acetate $(4: 1)$, some impurities were eluted. Patulin was then completely eluted with $10 \mathrm{~mL}$ of ethyl acetate.

The effect of clean-up by this proposed method, filtration under non-polar conditions and solid-phase extraction, was checked. The mass chromatograms in the SCAN mode of the sample after each clean-up step are shown in Fig. 2.

When $2 \mathrm{~mL}$ of "sample extract" was evaporated to dryness and taken up in $0.5 \mathrm{~mL}$ of BSTEA solution, some residue was not dissolved and the solution was deeply colored and very clouded. Therefore we could not apply this test solution to GC/MS. When "sample extract" was mixed with nine volumes of hexane, significant amounts of insoluble substances were produced. After filtration under non-polar conditions, it was possible to dissolve the cleaned-up sample in 0.5 $\mathrm{mL}$ of BSTEA solution. This filtration was very effective for purification, removing polar substances. The filtration was more effective for clean-up in hexaneethyl acetate $(9: 1)$ than in hexane-ethyl acetate $(4: 1)$, so hexane-ethyl acetate $(9: 1)$ was selected as the solvent for application to the cartridges. Without the solidphase extraction, an interfering peak near the patulin derivative remained (Fig. 2A, B). However, this interfering peak was effectively removed by the solid-phase extraction (Fig. 2C, D), and this test solution for GC/MS was clear and colorless or slightly colored. After the filtration under non-polar conditions and the solidphase extraction, patulin could be confirmed by mass spectrometry down to the $5 \mu \mathrm{g} / \mathrm{kg}$ level in samples.

\section{Selection of column for $G C / M S$}

Three kinds of capillary columns of moderately polar type, DB-17 $(0.25 \mu \mathrm{m}$ i.d. $\times 30 \mathrm{~m}, 0.25 \mu \mathrm{m}$ film thickness, J \& W), DB-1701 (0.25 $\mu \mathrm{m}$ i.d. $\times 30 \mathrm{~m}, 0.25 \mu \mathrm{m}$ film thickness, J \& W ) and BPX-35 $(0.22 \mu \mathrm{m}$ i.d. $\times 25 \mathrm{~m}, 0.25 \mu \mathrm{m}$ film thickness, BSE), were tested to determine and confirm patulin in samples. Although the determination of patulin in the SIM mode was possible with all tested columns, the best performance in the confirmation of patulin by mass spectrometry in the SCAN mode was achieved with the BPX-35 column; when analyzed with the other columns, some interfering fragment ion peaks derived from impurities disturbed the confirmation of patulin at low levels. The BPX-35 column was thus chosen for our method.

\section{Determination and confirmation}

The mass chromatogram of the sample is shown in Fig. 3. The monitored ions for the SIM mode were $\mathrm{m} / z$ 226, 183 and 170, based on their sensitivity and selectivity (Fig. 3). Although the sensitivity of $m / z 183$ was better than that of $m / z 226$, the best selectivity was obtained in the measurement at $\mathrm{m} / z 226$, the molecular ion of patulin trimethylsilyl ether. Thus, it was decided to determine patulin by using the ion $m / z 226$. No interfering peak was found near this peak of patulin derivative.

Good linearity with a correlation coefficient of 0.9997 was obtained in the range of 40 to $8,000 \mathrm{ng} / \mathrm{mL}$ concentration of the solution injected into GC/MS, equivalent to 1 to $200 \mu \mathrm{g} / \mathrm{kg}$ of patulin in samples. The limits of detection and quantification were $0.1(S / N=3)$ and 1 $\mu \mathrm{g} / \mathrm{kg}(\mathrm{S} / N=30)$ of patulin in samples, respectively.

As Fig. 4 shows, the mass spectrum of patulin trimethylsilyl ether in samples was in good agreement with that of the standard. Confirmation was possible at the concentration of $5 \mu \mathrm{g} / \mathrm{kg}$ of patulin in samples and sometimes even at the level of $3 \mu \mathrm{g} / \mathrm{kg}$. Confirmation from the mass spectrum obtained by GC/MS was con- 


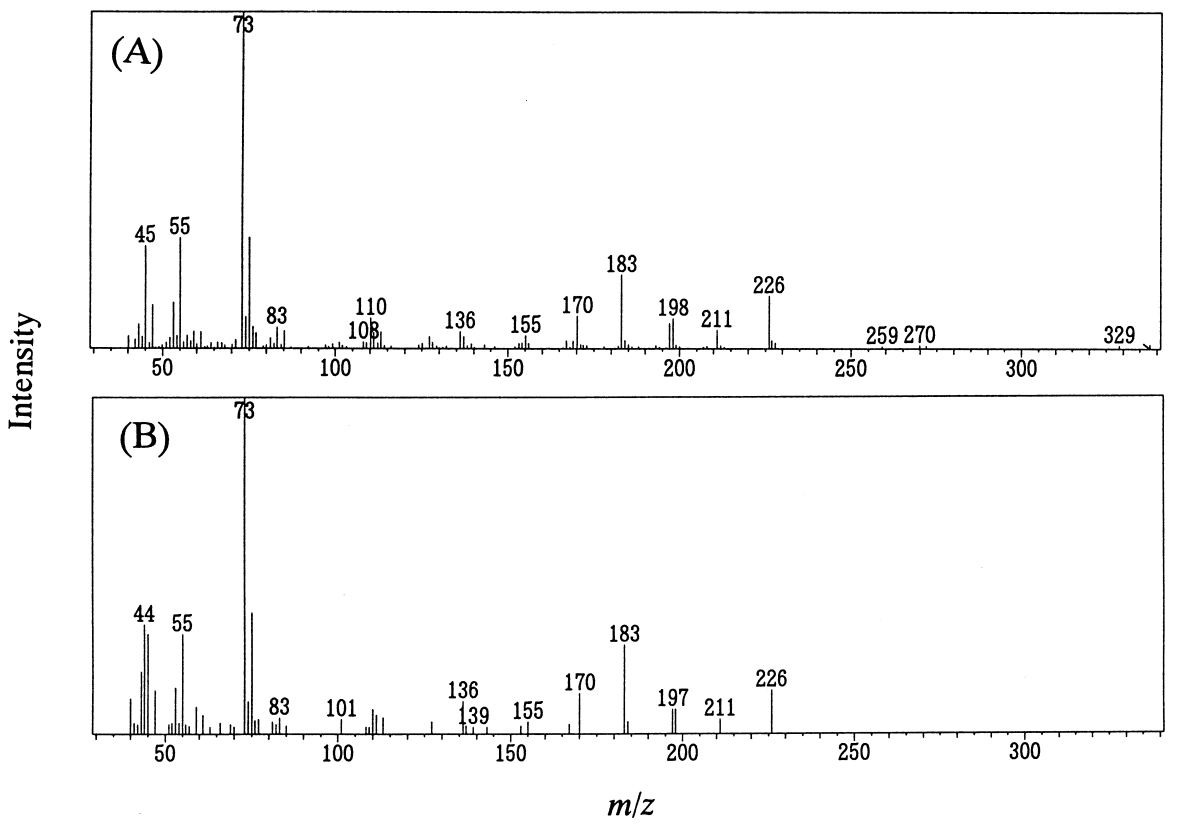

Fig. 4. Mass spectra of patulin derivative in sample (A) and standard (B) Patulin content in the sample: $5.5 \mu \mathrm{g} / \mathrm{kg}$.

Table 1. Recovery of Patulin Added to Apple Juice

\begin{tabular}{ccc}
\hline $\begin{array}{c}\text { Patulin added } \\
(\mu \mathrm{g} / \mathrm{kg} \text { in samples })\end{array}$ & $\begin{array}{c}\text { Mean recovery* } \\
(\%)\end{array}$ & $\begin{array}{c}\text { CV } \\
(\%)\end{array}$ \\
\hline 10 & 93.4 & 3.8 \\
20 & 94.9 & 2.4 \\
50 & 99.8 & 1.8 \\
500 & 100 & 1.6 \\
\hline
\end{tabular}

* Values are means of five trials.

sidered to be reliable.

\section{Recovery and effect of sample matrix}

Different amounts $(0.5,1.0,2.5$ and $25 \mu \mathrm{g})$ of patulin were added to $50 \mathrm{~g}$ of $100 \%$ pure apple juice $(n=5$, each), and the samples were analyzed by the proposed method. The recovery and CV values ranged from 93.4 to $100 \%$ and 1.6 to $3.8 \%$, respectively (Table 1 ).

The effect of the sample matrix on our GC/MS method was examined. No effect of the sample matrix on the sensitivity was observed. The recovery and $\mathrm{CV}$ values of the proposed method were sufficient for evaluation of apple juice samples.

\section{References}

1) Pitt, J. I., Hocking, A. D. eds., "Fungi and Food Spoilage", $2^{\text {nd }}$ Ed., Aspen Publishers, 1999, p. 314-316, 326-328. (ISBN 0-8342-1306-0)
2) Tabata, S., "Mycotoxin", Hosogai, Y., Matsumoto, M. (eds.), Tokyo, Chuohoki Publishers, 2002, p. 158-165. (ISBN 4-8058-2125-6)

3) FAO (ed.), "Worldwide regulations for mycotoxins 1995. A compendium, FAO Food and Nutrition Papers, Number 64", FAO, 1997, p. 7-38. (ISBN 92-5-103960-7)

4) Notification No. 369 (Nov. 26, 2003), Ministry of Health, Labour and Welfare, Japan.

5) Trucksess, M.W. (ed): Natural toxins, AOAC official methods of analysis, $17^{\text {th }}$ Ed., Chapter 49, p. 50-53 (2000).

6) Rupp, H. S., Turnipseed, S. B., Confirmation of patulin and 5-hydroxymethylfurfural in apple juice by gas chromatography/mass spectrometry. J. AOAC Int., 83, 612-620 (2000).

7) Roach, J. A. G., White, K. D., Trucksess, M. W., Thomas, F. S., Capillary gas chromatography/mass spectrometry with chemical ionization and negative ion detection for confirmation of identity of patulin in apple juice. J. AOAC Int., 83, 104-112 (2000).

8) Llovera, M., Viladrich, R., Torres, M., Canela, R., Analysis of underivatized patulin by a GC/MS technique. J. Food Prot., 62, 202-205 (1999).

9) Tarter, E. J., Scott, P. M., Determination of patulin by capillary gas chromatography of the heptafluorobutyrate derivative. J. Chromatogr., 538, 441-446 (1991).

10) Rychlik, M., Schieberle, P., Quantification of the mycotoxin patulin by a stable isotope dilution assay. J. Agric Food Chem., 47, 3,749-3,755 (1999). 